\title{
A Survey for Rhinitis in an Automotive Ring Manufacturing Plant
}

\author{
Dong-Uk PARK ${ }^{1,3 *}$, Ku-Won JIN', Dong-Hee KOH², Byung-Kyu KIM², \\ Kyu-Sang KIM ${ }^{2}$ and Doo-Yong PARK ${ }^{2,4}$
}

\author{
${ }^{1}$ Department of Environmental Health, Korea National Open University, Dongsungdong, Jongroku, Seoul, 110 - \\ 791, Korea \\ ${ }^{2}$ Center for Occupational Disease Research, Occupational Safety and Health Research Institute, Kosha, Korea \\ ${ }^{3}$ Occupational and Environmental Epidemiology Branch Division of Cancer Epidemiology and Genetics, NCI, \\ NIH, DHHS, US \\ ${ }^{4}$ Mechanical System Engineering, Hansung University, Korea
}

Received June 21, 2007 and accepted February 12, 2008

\begin{abstract}
We report findings regarding otolaryngologist-confirmed rhinitis, current exposure to MWF aerosols, fungi, and endotoxins for workers in a plant manufacturing automobile piston rings. Questionnaire data showed that $61.5 \%$ of 187 workers exhibited rhinitis-related symptoms. Rhinitis was confirmed in 99 of 115 workers whom were medically examined. Otolaryngologist-confirmed rhinitis was present in 10 of 19 grinding workers $(52.6 \%), 67$ of 142 production workers $(47.2 \%)$, and 22 of 26 quality control (QC) workers $(84.6 \%)$. These rates are much higher than the rates of rhinitis-related symptoms in automobile plants and other occupational settings and quite high even allowing for the common occurrence of rhinitis in the general population. We found that rhinitis could develop even in workers exposed to less than $0.5 \mathrm{mg} / \mathrm{m}^{3} \mathrm{MWF}$ aerosol. The average exposure to fungi exceeded $10 \times 10^{3} \mathrm{CFU} / \mathrm{m}^{3}$, a level higher than that reported for other automobile plants. Although we were unable to identify significant risk factors for rhinitis using only the physician-confirmed rhinitis cases, this study concludes that exposure to MWF aerosol, which would include microbes and metals, could contribute to a high occurrence of rhinitis in grinding and production workers. Forty-nine workers $(63.6 \%)$ of 77 rhinitis patients in grinding and production operations were determined to handle synthetic MWF directly. For QC workers, for whom the prevalence of physician-confirmed rhinitis was highest, exposure to a low level of MWF aerosol, including specific microbe species we couldn't identify, bright light, dry air, and certain work characteristics during inspection are possible risk factors for development of rhinitis. Further studies including identification of fungi species should be conducted so a firm conclusion can be made regarding the development of rhinitis in QC manufacturing plant workers.
\end{abstract}

Key words: Rhinitis, Metalworking fluids (MWF), MWF aerosol, Grinding operation

\section{Introduction}

Rhinitis is inflammation of the mucosa (surface cells) of the nose. It causes such symptoms as sneezing, runny nose (rhinorrhea), postnasal drip, and congestion. It is widely known to be one of three common diseases associated with exposure to mold, dust mites, pets, environ-

*To whom correspondence should be addressed. mental tobacco smoke, and irritants ${ }^{1-3)}$.

Studies of the effects of occupational exposure on the development of rhinitis are sparse. Some studies have reported an association between occupational environments and frequent rhinitis symptoms. Rhinitis is three times more prevalent than asthma among workers exposed to laboratory animal allergens ${ }^{4)}$. A high prevalence of rhinitis symptoms was reported among bakers exposed to flour dust and its additives ${ }^{5)}$, among workers exposed to 
chlorine ${ }^{6)}$, and among pulp-mill workers exposed to ozone $^{7}$. Hellgren et $a l .{ }^{8)}$ reported that exposure to airborne irritants such as wood dust, paper dust, and cleaners is associated with a higher risk of developing noninfectious rhinitis.

Workers in plants manufacturing automobile parts are exposed to a variety of chemical and biological agents that might be associated with the development of respiratory disease, including rhinitis. Although there is an established association between exposure to metalworking fluids (MWFs) and respiratory diseases such as asthma and hypersensitivity pneumonitis ${ }^{9-14)}$, little is known about the related risk of rhinitis. Physician-confirmed cases of rhinitis have been rarely reported in studies to date.

In a study by Rosenman et al. ${ }^{9)}$, the percentage of workers exposed to MWFs reporting that they visited a doctor for sinus problems ranged between $29.4 \%$ (exposure to straight MWF only) and $48.1 \%$ (exposure to synthetic MWF only). In Oudyk et al.'s study ${ }^{15)}$ of the effects of exposure to MWFs on respiratory symptoms, $42 \%$ of 2,377 workers exposed to water-soluble MWFs reported "runny nose or plugged nose on a weekly or daily basis". Recently, Park et al. ${ }^{16)}$ investigated the association between nose-related respiratory symptoms and exposure to water-soluble MWFs in an automobile engine plant, but found no significant difference in symptoms between workers who did and did not handle MWF. According to Park et al.'s study ${ }^{16)}, 10.4 \%$ to $31.3 \%$ of nose-related symptoms or problems have been noted among workers in automobile-part manufacturing plants that use water-soluble MWFs.

We believe that the lack of evidence linking exposure to MWFs or other work conditions to the development of rhinitis is due to the fact that rhinitis is considered a minor disease and common even in the absence of workplace exposure. We conducted an epidemiological study that included quantitative assessment of current exposure to chemical and biological agents, a questionnaire regarding rhinitis-related symptoms, and medical examination for sinus-related disease. In this article, we report our findings regarding Otolaryngologist-confirmed rhinitis. An association between development of rhinitis and use of MWFs as well as other occupational factors is briefly discussed.

\section{Methods}

\section{Study plant and operations}

The study plant manufactures piston rings for automobiles. The plant began operations in Seoul, Korea in 1959. It moved to another city in 1975 and moved again to its current location in 2001, bringing most of its work- ers. The plant has two main lines, casting and production, which are separately located and operated. The casting line roughly manufactures the molds for the rings. The molds are refined and made into actual rings in the production line, which consists of grinding, manufacturing, and quality control (QC) operations.

Because the production line uses synthetic MWFs and because workers in the production line have frequently reported nasal symptoms, the production line was chosen for detailed evaluation of operation characteristics and quantitative assessment of worker exposure to agents. The casting line was not included in the investigation.

\section{Quantitative assessment of current exposure to MWFs and biological agents \\ Current exposure to MWFs was assessed on the basis} that it is suitable for estimating the risk of acute or subchronic health effects such as rhinitis. Workers from the grinding, manufacturing, and QC operations were grouped based on similar exposure in terms of the characteristics of operation, environmental hazards and work practice, which refers to similar exposure group (SEG). Workers representing each SEG by operation were randomly selected for assessment of exposure to environmental hazards that are known to be associated with the development of sinus-related disease. Exposures to MWF aerosols and biological agents (fungi and endotoxins) in the breathing zone of the representative production line workers were assessed.

Airborne MWF mists from the breathing zone were measured using the sampling and analytical methods recommended by the National Institute for Occupational Safety and Health ${ }^{17}$. Endotoxin concentrations were quantified using the Kinetic Turbidimetric Limulus Amoebocyte Lysate method (Pyrogent-5000, BioWhittaker, Walkersville, MD) of the American Society for Testing and Materials (E2144-01) ${ }^{18)}$. Airborne microorganisms such as viable bacteria and fungi were collected and analyzed using the CAMNEA method, as recommended by Palmgren et al. ${ }^{19)}$.

\section{Questionnaire and medical examination}

One hundred eighty-seven workers working on the production line at the time of the study who did not have a history of respiratory disease were invited to participate in a questionnaire with the assistance of trained interviewers. The questionnaire addressed the presence, frequency and severity of rhinitis-related symptoms such as nasal congestion, nasal secretion, itching, and sneezing. Demographic information, including lifestyle, and occupational history were collected. Production workers who complained of rhinitis-related symptoms were medically examined by an otolaryngologist to determine the pres- 
Table 1. Characteristics of the study population according to rhinitis status

\begin{tabular}{|c|c|c|c|c|c|}
\hline & \multirow{2}{*}{ Male/female } & \multirow{2}{*}{$\begin{array}{l}\text { Age (years, } \\
\text { mean } \pm \text { SD) }\end{array}$} & \multirow{2}{*}{$\begin{array}{l}\text { Duration of employment } \\
\quad(\text { years, mean } \pm S D)\end{array}$} & \multicolumn{2}{|c|}{ Smoking status ${ }^{\mathrm{a}}$} \\
\hline & & & & Smoker & Non-smoker \\
\hline Rhinitis ( $n=99$ ) & $86 / 13$ & $38.1 \pm 9.3$ & $14.0 \pm 9.2$ & 37 & 46 \\
\hline No rhinitis $(n=88)$ & $88 / 0$ & $39.6 \pm 9.7$ & $14.2 \pm 8.9$ & 38 & 47 \\
\hline
\end{tabular}

${ }^{\mathrm{a}} 19$ missing values.

ence of sinus-related diseases such as rhinitis, allergic rhinitis, nonallergic rhinitis, chronic sinusitis, perennial allergic rhinitis, nasal septum deviation, hypertrophic rhinitis, hyposmia, seasonal allergic rhinitis, and nasal polyps. Allergic rhinitis was diagnosed using skin prick test with 10 common inhalable allergens, such as Alternaria, Aspergillus, Grass pollen, Tree pollen, Cat fur, Cockroach, D. farinae, D. pteronyssinae, Mugwort, Ragweed. In addition, all workers from the grinding (19) and QC operations (26) underwent physical examination because they reported respiratory symptoms more frequently than did the other manufacturing workers. Both $\mathrm{X}$-ray and computed tomography (CT) were examined to diagnose rhinitis. SPSS 15.0 for Windows was used to conduct $\chi^{2}$ test to compare general characteristics among three operations.

\section{Results}

\section{Worker characteristics}

General variables that might affect the development of rhinitis such as age, duration of employment, and smoking status did not differ between workers with and without rhinitis (Table 1). The general characteristics of the 99 workers diagnosed with rhinitis were compared across the three operations (Table 2). The three worker groups differed with respect to sex $(p=0.000)$ and smoking status $(p=0.005)$. In particular, $53.8 \%$ of QC workers were female while all workers from the other two operations were male. There were significantly fewer smokers in the QC operation compared to the other two operations. The average age of QC workers was 33.1 yr (range 22-58 yr), lower than that for the other two operations. Approximately half of the QC workers (54.5\%) were less than $30 \mathrm{yr}$ old. The age of female QC workers ranged from 22-35 yr. However, age and duration of employment did not significantly differ across the three operations. No general characteristic significantly confounding the difference in prevalence of rhinitis across operations was found.

\section{Operation characteristics}

The incomplete rings are initially sent from the casting line to the grinding operation, where the ring surfaces are
Table 2. General characteristics of 99 workers diagnosed with rhinitis, according to plant operation

\begin{tabular}{|c|c|c|c|c|}
\hline & $\begin{array}{l}\text { Grinding } \\
(n=10)\end{array}$ & $\begin{array}{c}\text { Manufacturing } \\
(n=67)\end{array}$ & $\begin{array}{c}\mathrm{QC} \\
(n=22)\end{array}$ & $p$-value \\
\hline Sex & & & & 0.000 \\
\hline Male & 10 & 67 & 9 & \\
\hline Female & 0 & 0 & 13 & \\
\hline Age (yr) & & & & 0.091 \\
\hline$<30$ & 3 & 12 & 10 & \\
\hline $30-39$ & 3 & 24 & 4 & \\
\hline $40-50$ & 2 & 24 & 5 & \\
\hline$>50$ & 2 & 7 & 3 & \\
\hline Smoking status ${ }^{\mathrm{a}}$ & & & & 0.005 \\
\hline Yes & 4 & 24 & 3 & \\
\hline No & 4 & 30 & 18 & \\
\hline $\begin{array}{l}\text { Duration of } \\
\text { employment (yr) }\end{array}$ & & & & 0.080 \\
\hline$<5$ & 3 & 13 & 4 & \\
\hline $5-10$ & 1 & 9 & 8 & \\
\hline$>10$ & 6 & 45 & 10 & \\
\hline
\end{tabular}

a 16 missing values.

roughly ground using synthetic MWF. Next, the three manufacturing operations finely grind the inner and outer parts of the rings as well as the surface using the same synthetic MWF. Finally, the rings are inspected and assembled in the QC operation. QC workers are responsible for selecting rings that do not meet the specified quality criteria. This is accomplished via visual inspection under a fluorescent lamp. Rings that do not meet the criteria are dropped into a plastic box under the table; workers assemble the rings that pass inspection (Fig. 1). QC workers continuously sit at a table during working hours. Due to lack of local exhaust ventilation, they are continually exposed to a small amount of MWF, microbes, and metal left on the surface of the rings. In addition, they are continuously exposed to bright glare from a lamp $(36 \mathrm{~W})$ within their breathing zone.

Current exposure to MWF mist, endotoxins, and microbes

Nearly all workers were exposed to concentrations of MWF mist higher than $0.2 \mathrm{mg} / \mathrm{m}^{3}$ of the threshold limit value listed as a notice of intended change by the American Conference for Governmental Industrial 


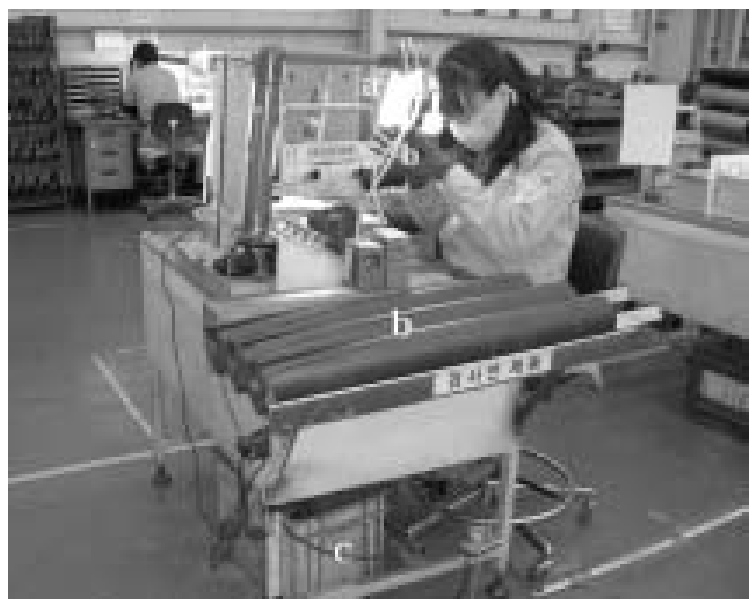

Fig. 1. Working posture of QC workers who inspect and assemble piston rings for automobiles.

A female worker is inspecting the quality of rings under a fluorescent lamp.

a: fluorescent lamp, b: piston ring for inspection, c : box collecting poor quality rings

Table 3. Exposure to MWF mists, endotoxins, and fungi, according to plant operation

\begin{tabular}{cccc}
\hline Operation & $\begin{array}{c}\text { MWF mist } \\
\left(\mathrm{mg} / \mathrm{m}^{3}\right)\end{array}$ & $\begin{array}{c}\text { Endotoxins } \\
\left(\mathrm{EU} / \mathrm{m}^{3}\right)\end{array}$ & $\begin{array}{c}\text { Culturable fungi } \\
\left(\mathrm{CFU} / \mathrm{m}^{3}\right)\end{array}$ \\
\hline Grinding & & & 12 \\
Sample number & 12 & 12 & 12 \\
Mean (range) & 0.85 & 11.4 & $1.1 \times 10^{5}$ \\
$(0.05-7.65)$ & $(6.1-44.3)$ & $\left(19-5.4 \times 10^{5}\right)$ \\
Manufacturing & & & 22 \\
Sample number & 22 & 22 & $1.1 \times 10^{5}$ \\
Mean (range) & 0.48 & 8.3 & $\left(7-2.7 \times 10^{6}\right)$ \\
QC & $(0.18-1.38)$ & $(3.8-19.4)$ & 10 \\
Sample number & 11 & 11 & $1.6 \times 10^{3}$ \\
Mean (range) & 0.26 & 3.2 & $\left(6.9 \times 10^{2}-4.3 \times 10^{3}\right)$ \\
\hline
\end{tabular}

Hygienists ${ }^{20)}$. Exposure of workers in the grinding operation to MWF mist averaged $0.85 \mathrm{mg} / \mathrm{m}^{3}$, which is above the recommended exposure level (REL) of $0.5 \mathrm{mg} / \mathrm{m}^{321}$.

Exposures to MWF mist, fungi, and endotoxins were highest for the grinding workers, lower for production workers, and lowest for QC workers (Table 3).

Most workers were exposed to fungi levels above $10^{3}$ $\mathrm{CFU} / \mathrm{m}^{3}$. All exposures to endotoxins were lower than the $50 \mathrm{EU} / \mathrm{m}^{3}$ limit of occupational exposure proposed by the National Health Council of the Netherlands ${ }^{22}$. Exposures to other chemical agents including chromium and ethanolamine (data not shown) were far too low to adversely affect workers' respiratory health. The humidity in the QC operation ranged from $27.5-32.7 \%$ during
Table 4. Prevalence of rhinitis according to plant operation

\begin{tabular}{lccrr}
\hline \multicolumn{1}{c}{ Type of rhinitis } & Grinding & Manufacturing & QC & Total \\
\hline Nonallergic rhinitis & 6 & 25 & 10 & 41 \\
Allergic rhinitis & 2 & 24 & 10 & 36 \\
Sinusitis & 1 & 3 & 0 & 4 \\
Other $^{\mathrm{a}}$ & 1 & 15 & 2 & 18 \\
\hline Number of patients & 10 & 67 & 22 & 99 \\
Number of workers & 19 & 142 & 26 & 187 \\
Prevalence (\%) & 52.6 & 47.2 & 84.6 & 52.9 \\
\hline
\end{tabular}

ancludes sinusitis, nasal septum deviation, hypertrophic rhinitis, hyposmia, seasonal allergic rhinitis, and nasal polyps.

working hours (mean 29\%); this was lower than for the two other operations (31.2-43.8\%). Irritants such as ozone, $\mathrm{NO}_{2}$, and $\mathrm{SO}_{2}$ that are known to be related to an increase in healthcare visits for allergic rhinitis ${ }^{7,23)}$ were not detected in the production line.

\section{Physician-confirmed rhinitis}

Of 187 workers interviewed, 115 exhibited rhinitisrelated symptoms and underwent physical examination. Ninety-nine of 115 workers were diagnosed with rhinitis. Table 4 summarizes the prevalence rate by rhinitis type. Nonallergenic and allergenic rhinitis accounted for $78.8 \%$ of cases; this prevalence was much higher than that of other rhinal-related diseases. Paranasal sinusitis, sinusitis, and nasal polyps were also found, but the prevalence was low. Rhinitis was confirmed in 22 of 26 QC workers $(84.6 \%)$. This was the highest prevalence among the three operations, despite the fact that QC workers had lower exposures to MWF mist and microbes. All 12 male QC workers and 10 of 14 female QC workers developed rhinitis. Of workers who underwent the allergic skin prick test using ten allergens including Aspergillus and Alternaria, only one workers who are working at grinding operation showed positive response to Alternaria.

\section{Discussion}

Many studies conducted in indoor environmental settings have shown that most cases of allergic and nonallergic rhinitis are caused by bacterial and fungal infections $^{2,24-29)}$. In automobile plants using water-soluble MWFs like synthetic MWFs, exposure to MWF aerosol, including microbes, their toxins, and other metallic elements could contribute to the etiology and exacerbation of respiratory diseases.

Several studies conducted in automobile plants that use MWFs reported respiratory complaints, asthma, upper respiratory symptoms, or HP in workers exposed to $\left.\mathrm{MWFs}^{9}, 10,14,30\right)$. Many studies have shown that there is 
a significant association between exposure to MWFs and the development of asthma in automobile workers $9,10,14,21,30,31)$. Based on epidemiological studies presenting strong evidence for an association between asthma and rhinitis ${ }^{26,32-34)}$, it seems likely that workers at automobile plants that use MWFs are at risk for rhinitis.

There have been few studies of rhinitis in plants using MWFs. In this study, we found a high prevalence of physician-confirmed rhinitis in workers involved in the manufacturing of automobile rings. Because physicianconfirmed rhinitis avoids reliance on the subjective selfreport of respiratory symptoms by study workers, our results could help to inform the causes and risk of rhinitis in automobile part manufacturing plants that use MWFs.

The automobile plant that we studied houses grinding, manufacturing, and QC operations. We found that 99 of 187 workers $(52.9 \%)$ were medically diagnosed with rhinitis (Table 4). The prevalences of rhinitis-related symptoms (61.5\%) and clinically diagnosed rhinitis (52.9\%) are higher than those previously reported for automobile plants using $\mathrm{MWFs}^{9,15,16,35)}$. Ameille et al. ${ }^{35)}$, reported that the prevalence of rhinitis was $15.8-17.6 \%$ in workers handling soluble and straight MWF. Rosenman et al. ${ }^{9)}$ reported that $37.3 \%$ (emulsified MWFs), $42.9 \%$ (semi-synthetic MWFs), and 48.1\% (synthetic MWFs) of workers exposed to MWFs visited a doctor for sinus problems. The number of workers experiencing nasal stuffiness symptoms daily or weekly ranged from $25.1-42.9 \%$. Oudyk et al. ${ }^{15)}$ reported that $42 \%$ of 2,935 employees working at a large automotive machining location complained a runny or plugged nose symptoms daily or weekly.

This high prevalence of rhinitis was found despite the fact that current worker exposure to MWF aerosol was below $0.5 \mathrm{mg} / \mathrm{m}^{3}$. Exposure to MWF mist was below the range $\left(0.59-2.12 \mathrm{mg} / \mathrm{m}^{3}\right)$ reported by Park et al. ${ }^{36)}$ for a Korean plant manufacturing automobile engines. That plant involved operations similar to this study, and several sinusitis cases were reported. However, exposure to MWF mist was generally higher than the exposures reported in several other studies finding cases of $\mathrm{HP}^{10,14)}$, cross-shift decrement ${ }^{30)}$, or a high prevalence of respiratory symptoms in automobile plants ${ }^{9,14)}$. Our findings confirm the NIOSH contention that nonmalignant respiratory diseases like rhinitis can develop even with exposure below its REL $\left(0.5 \mathrm{mg} / \mathrm{m}^{3}\right)^{21}$. To date, there is no suggested limit for occupational exposure to MWF aerosol to protect against nonmalignant respiratory diseases such as asthma, rhinitis, and HP.

We initially hypothesized that exposure to microbes would cause workers handling synthetic MWFs to exhibit more rhinitis or rhinitis-related symptoms than QC workers who do not handle MWF directly. However, the prevalence of confirmed rhinitis was highest for QC workers. This prevalence $(84.6 \%)$ is quite high, even allowing for the fact that rhinitis is relatively common in the absence of workplace exposure. To our knowledge no other study has reported a higher prevalence of rhinitis than the results presented here. Ameille et al. ${ }^{35)}$, reported that the prevalence of rhinitis was present in $14.1 \%$ of the assemblers who performed no machining operations with MWF.

Identification of causative occupational factors can be especially difficult when the health outcome of concern is relatively common-even in the absence of workplace exposure. Such is the case with rhinitis.

Our study assumed that exposure to MWF aerosol, including microbes, endotoxins, and metals, is related to the development of rhinitis in workers involved in grinding and manufacturing operations at plants manufacturing automobile parts. This assumption may be supported by our finding that $49(63.6 \%)$ of 77 rhinitis patients in grinding and manufacturing operations were determined to handle synthetic MWF directly. However, considering that QC workers were exposed to less fungi, endotoxins, and MWF aerosol than were workers in the other two operations (Table 3), we conclude that the high prevalence of rhinitis in the QC operation is related to occupational or workplace factors other than MWF aerosols.

Our industrial hygiene investigation into QC operation considered three factors (exposure to low humidity, exposure to bright light, and working posture with head tilted forward) not discovered in the two other operations as possible contributors to the high prevalence of rhinitis for QC workers, although we could not identify risk factors for rhinitis using only physician-confirmed cases of rhinitis. In addition, QC workers are consistently exposed to direct glare from a fluorescent lamp $(32 \mathrm{~W})$ within their breathing zone. These factors are in agreement with Middleton's study ${ }^{37)}$ showing that non-allergic rhinitis patients frequently report congestion or rhinorrhea in response to changes in air temperature, humidity, exposure to bright light, etc. QC workers also sit in one posture during working hours, with head tilted forward to inspect handfuls of rings (Fig. 1). Although forward tilt of the head has not yet been associated with the development of rhinitis, it may be related to high prevalence of the condition.

This field study failed to demonstrate any meaningful association between a prevalence rhinitis rate and either level of MWF mist or bioaerosol levels (fungi and endotoxin) although prevalence rate of rhinitis from workers handling synthetic MWF is found to be higher than those reported (Table 4). In addition, we can't identify a significant factor to cause higher rhinitis rate from QC work- 
ers than other operation workers. There could be limitations of this study that may relate to lack of relationship. First, investigation for identification of specific fungi species was not conducted. Unfortunately, further medical examination such as nasal provocation and serum specific antibody tests couldn't be conducted to identify the fungi species that may cause rhinitis. Second, we did not assess exposure to either MWF-related contaminants or components or specific microbe species that may be associated with rhinitis risk, although other occupational factors such as bright light and working practices were suggested. In spite of those limitations, this field study could be guide to recognize the occupational factors that may cause the development of rhinitis in synthetic MWF using plants.

\section{Conclusions}

The prevalence of physician-confirmed rhinitis in a plant manufacturing piston rings for automobiles was higher than all rates previously reported for automobile plants and other occupational settings. We conclude that exposure to MWF aerosol, including microbes, endotoxins, and metals, is related to the development of rhinitis in workers involved in grinding and manufacturing operations at plants manufacturing automobile parts. In addition, we propose that the high prevalence of physicianconfirmed rhinitis $(84.6 \%)$ in workers inspecting and assembling automobile rings may be linked to exposure to glaring light and dry air in the workplace, working posture, and low levels of exposure to MWF aerosol containing microbes. Further studies should be conducted so a firm conclusion can be made regarding the development of rhinitis in QC manufacturing plant workers.

\section{References}

1) Shusterman D (2002) Review of the upper airway, icluding olfaction, as mediator of symptoms. Environ Health Perspect 110, 649-53.

2) Wang D (2005) Risk factors of allergic rhinitis: genetic or environmental? Ther Clin Risk Manag 1, 115-23.

3) Biagini J, LeMasters G, Ryan P, Levin L, Reponen T, Bernstein D, Villarea M, Khurana Hershey G, Burkle J, Lockey J (2006) Environmental risk factors of rhinitis in early infancy. Pediatr Allergy Immunol 17, 278-84.

4) Bush R, Wood R, Eggleston P (1998) Laboratory animal allergy. J Allergy Clin Immunol 102, 99-112.

5) Brisman J, Jarvholm B (1999) Bakery work, Atopy and the incidence of self-reported hay fever and rhinitis. Eur Respir J 13, 502-7.

6) Leroyer C, Malo J, Girard D, Dufour J, Gautrin D (1999) Chronic rhinitis in workers at risk of reactive airway. Occup Environ Med 56, 334-8.
7) Hoffman C, Henneberger P, Olin A, Mehta A, Toren K (2004) Exposure to ozone gases in pulp mills and the onset of rhinitis. Scand J Work Envion Health 30, 445-9.

8) Hellgren J, Lillienberg L, Jarlstedt J, Karlsson G, Toren K (2002) Population-based study of non-infectious rhinitis in relation to occupational exposure, age, sex and smoking. Am J Ind Med 42, 23-8.

9) Rosenman K, Reilly M, Kalinowski D (1997) Workrelated asthma and respiratory sypmtoms among worekrs exposed to metalworking fluids. Am J Ind Med 32, 325-31.

10) Kreiss K, Cox-Ganser J (1997) Metalworking fluidassociated hypersensitivity pneumonitis: a workshop summary. Am J Ind Med 32, 423-32.

11) Kennedy S, Chan-Yeung M, Teschke K, Karlen B (1999) Change in airway responsiveness among apprentices exposed to metalworking fluids. Am J Respir Crit Care Med 159, 87-93.

12) Abrams L, Seixas N, Robins $T$, Burge H, Muilenberg M, Franzblau A (2000) Characterization of metalworking fluid exposure indices for a study of acute respiratory effects. Appl Occup Environ Hyg 15, 492-502.

13) Jones R (2002) Microbiology of newer fluoroquinolones: focus on respiratory pathogens. Dia Micro and Inf Dis 44, 213-20.

14) Bracker A, Storey E, Yang C, Hodgson M (2003) An outbreak of hypersensitivity pneumonitis at a metalworking plant: a longitudinal assessment of intervention effectiveness. Appl Occup Environ Hyg 18, 96-108.

15) Oudyk J, Haines A, D’Arcy J (2003) Investigation respiratory responses to metalworking fluid exposure. Appl Occup Environ Hyg 18, 939-46.

16) Park D, Chin B, Kim S, Kwag H, Joo K, Jongdeuk J (2005) Exposure assessment to suggest the cause of sinusitis developed in grinding operations utilizing soluble metalworking fluids. J Occup Health 47, 319-26.

17) National Institute for Occupational Safety and Health (NIOSH) (1999) Method 0500. In: NIOSH manual of analytical methods, 4th Ed., S/N 94-113. U.S. government printing office, Washington, DC.

18) American Society for Testing and Materials (ASTM) (2001) "ASTM Designation E2144-01"; standard practice for personal sampling and analysis of endotoxin in metalworking fluid aerosol in workplace atmospheres. ASTM, Philadelphia.

19) Palmgren U, Strom G, Blomquist G, Malmberg P (1986) Collection of airborne micro-organism on Nuclepore filters, estimation and analysis-CAMNEA method. J Appl Bacteriol 61, 401-6.

20) American Conference of Governmental Industrial Hygienists (ACGIH) (2004) Threshold Limit Values and Biological Exposure Indices. ACGIH, Cincinnati.

21) National Institute for Occupational Safety and Health (NIOSH) (1998) Criteria for a recommended standard: Occupational exposure to metalworking fluids. U.S. Department of Health and Human Services, Public 
Health Service, Centers for Disease Control and Prevention, National Institute for Occupational Safety and Health, Cincinnati.

22) Dutch Expert Committee on Occupational Standards (DECOS) (1997) Health based recommended occupational exposure limit for endotoxins. Health Council of the Netherands, Rijswijk.

23) Hajat S, Haines A, Atkinson RW, Bremner SA, Anderson HR, Emberlin J (2001) Association between air pollution and daily consultations with general practitioners for allergic rhinitis in London, United Kingdom. Am J Epidemiol 153, 704-14.

24) Benedictis F, Miraglia M, Severini S, Bonifazi F (2001) Rhinitis, sinusitis and asthma: one linked airway disease. Paediatr Respir Rev 2, 358-64.

25) Skoner D (2001) Allergic rhinitis: definition, epidemiology, pathophysiology, detection, and diagnosis. J Allergy Clin Immunol 108, 2-8.

26) Guerra S, Robert A (2002) Rhinitis as an independent risk factor for adult-onset asthma. J Allergy Clin Immunol 109, 419-25.

27) Baroody F (2003) Allergic rhinitis: broader disease effects and implications for management. Ocolaryngol Head Neck Surg 128, 616-31.

28) Dykewicz M (2003) Rhinitis and sinusitis. J Allergy Clin Immunol 111, 520-9.

29) Douwes J, Thorne P, Pearce N, Heederik D (2003) Bioaerosol health effects and exposure assessment: progress and prospects. Ann Occup Hyg 47, 187-200.

30) Robins TG, Seixas N, Franzblau A, Abrams L, Minick S, Burge H (1997) Acute respiratory effects on workers exposed to metalworking fluid aerosols in an automotive transmission plant. Am J Ind Med 31, 510-24.

31) Savonius B, Keskinen H, Tuppurainen M, Kanerva L (1994) Occupational asthma caused by ethanolamines.
Allergy 49, 877-81.

32) Gireisner WA III, Sattipane RJ, Settipane GA (1998) Co-existence of asthma and allergic rhinitis: a 23-year follow-up study of college students. Allergy Asthma Poc 19, 185-8.

33) Yawn BP, Yunginger JW, Wollan PC, Reed CE, Silverstein MD, Harris AG (1999) Allergic rhinitis in Rochester, Minnesota residents with asthma: frequency and impact on health care charges. J Allergy Clin Immunol 103, 54-9.

34) Leynaert B, Neukirch F, Demoly P, Bousquet J (2000) Epidemiologic evidence for asthma and rhinitis comorbidity. J Allergy Clin Immunol 106(Suppl. 5), 201-5.

35) Ameille J, Wild P, Choudat D, Ohl G, Vaucouleur J, Chanut J, Brochard P (1995) Respiratory symptoms, ventilatory impairment, and bronchial reactivity in oil mist-exposed automobile worker. Am J Ind Med 27, 247-56.

36) Park D, Chin K, Kwag H, Youn K, Choi S, Ha K, Yoon C, Yim S (2007) Effect of metalworking fluid mist exposure on cross-shift decrement in peak expiratory flow. J Occup Health 49, 25-31.

37) Middleton E (1988) Chronic rhinitis in adults. J Allergy Clin Immunol 81, 971-5.

38) Kriebel D, Sama S, Woskie S, Christini D, Eison E, Hammond S, Milton D, Smith M, Virji M (1997) A field investigation of the acute respiratory effects of metal working fluids. I. effects of aerosol exposures. Am J Ind Med 31, 756-66.

39) Kurup V, Shen H, Banerjee B (2000) Respiratory fungal allergy. Microbes Infect 2, 1101-10.

40) Shusterman D, Murphy M, Balmes J (2001) The influence of sex, allergic rhinitis, and test system on nasal sensitivity to airborne irritants: a pilot study. Environ Health Perspect 109, 15-9. 